\title{
Frida Kahlo: la mirada del cine
}

\author{
Frida, naturaleza viva | Paul Leduc, 1983 | Frida | Julie Taymor, 2002
}

\section{Delphine Scotto Di Vettimo*}

\author{
Aix-Marseille Université
}

Recepción: 15 de diciembre de 2019; aceptación: 2 de febrero de 2020

\begin{abstract}
Resumen
La biografía fílmica Frida [2002] de la directora estadounidense Julie Taymor, relata la vida de la pintora mexicana: su tormentosa vida desde su juventud estudiantil, su accidente y su relación apasionada con el muralista Diego Rivera. Numerosas referencias de los cuadros de Frida Kahlo están incluidos en la escenografía y recuerdan la riqueza y la complejidad de su obra: más de ciento cuarenta cuadros de los cuales una cincuentena autorretratos se traducen en diferentes temáticas: la política, la mexicanidad, el amor, la naturaleza, el sufrimiento, la femineidad e incluso la muerte. Es partir del análisis de una escena en particular (que refleja lo extremo de la experiencia del aborto y ofrece un sustento a la expresión de la temporalidad propia de este evento, el cual calificaremos de traumático) que el presente artículo, situado en el entrecruzamiento entre el cine y el psicoanálisis, explicita una etapa decisiva del proceso creador de Frida Kahlo. Aquí, el examen de la dialéctica entre el proceso creador y lo traumático, permite percibir, en su fase inicial la puesta en marcha de modalidades de creación artística que marcan una temporalidad inédita en su arte pictórico. Al mismo tiempo, el desafío del biopic es alcanzar por un lado a construir, plasmar, poner en escena y en imágenes la vida de esta artista fuera de lo común; y por otro lado permitir al espectador descubrir el entrelazamiento entre la subjetividad creadora y la obra de un artista.
\end{abstract}

Palabras clave: Cine | Proceso creador | Psicoanálisis |Trauma

Frida Kalbo: the look of cinema

\begin{abstract}
The film biography titled Frida [2002] produced by the American director and director Julie Taymor, relates the life of the Mexican painter while being inspired mainly by the book which devoted Hayden Herrera to him. It recounts the tumultuous life of the artist since his young student life, his accident and his passionate relationship with the muralist Diego Rivera.

Numerous references to Frida Kahlo's paintings are included in the scenography and recall the richness and complexity of her work: more than one hundred and forty paintings, of which fifty are self-portraits, which come in different themes: politics, Mexicanism, love, nature, suffering, femininity or even death.

It is from the analysis of a particular scene [which galvanizes the radicality of the abortion test and offers a framework for the expression of the temporality specific to this event, which I qualify as traumatic] that this article, which stands at the crossroads of cinema and psychoanalysis, explains a decisive stage in the creative process in Frida Kahlo.

Here, the examination of the dialectic between creative process and trauma, allows us to grasp, in the nascent state, the implementation of modes of pictorial creation which sign a new temporality in his pictorial art.

Beyond that, the challenge of the biopic is to succeed on the one hand in weaving, modeling, staging and images the life of this extraordinary artist; and on the other hand to allow the spectator to discover the entanglement between the creative subjectivity of the artist and his work.
\end{abstract}

Keywords: Cinema | Creative process | Psychoanalysis | Trauma

Iniciaremos el presente trabajo con el siguiente pasaje de una carta de Frida Kahlo dirigida a Alejandro Gómez Arias [29 septiembre 1926]: «Hace poco, casi unos días, era una niña que caminaba por un mundo de colores. $[\ldots]$ Todo era misterioso [...] Ahora habito en un planeta doloroso, transparente, como de hielo, pero que nada oculta». ${ }^{1}$

\section{Prolegómenos}

La obra pictórica y magistral de Frida Kahlo (19071954) fue catalogada en numerosas ocasiones de «autobiográfica» principalmente a causa de la prolífica serie de autorretratos, retratos y pinturas muy personales, de los cuales la pintora dirá: «Nunca pinté mis sueños.

* delphine.scotto-di-vettimo@univ-amu.fr 
Pinté mi propia realidad» ${ }^{2}$ en una expresión inequívoca. Esta perspectiva tan particular, al igual que estas afirmaciones formuladas por la artista, como también sus numerosas fuentes de inspiración provenientes de la literatura, de la medicina y del arte, servirán de hilo conductor para abordar su obra, teniendo en cuenta a la vez la teoría freudiana y lacaniana sobre la creación artística.

Frida Kahlo, proclamada como la «la mejor pintora de principio del siglo XX», se vio afectada primero por la poliomielitis, a los seis años, luego por un terrible accidente de autobús a los dieciocho, padeciendo secuelas físicas y corporales irreversibles, un matrimonio caótico, una vida también marcada por tres perdidas de embarazo, la imposibilidad de tener hijos y por último una muerte prematura a la edad de cuarenta y siete años: Frida Kahlo tiene todo para incluirse en el prototipo de artistas calificados de [doloriste $]^{3}$. Como es sabido, ella utilizó su experiencia personal, conyugal, afectiva como así también su cuerpo, su intimidad como un sitio de introspección, de autoanálisis ${ }^{4}$ y de inspiración, en el que la pintura restaura su quintaesencia.

En oportunidad de una exposición sobre la obra de Frida Kahlo y Diego Rivera en el Museo de la Orangerie en Paris ${ }^{5}$ me surgió el deseo de trabajar la función del objeto de arte y la manera en el que este puede efectivamente interpelarnos, convocarnos e incluso desestabilizarnos. En otras palabras: encontrarnos atrapados, llevados y atravesados por los destellos pintorescos de los lienzos de Frida Kahlo, sus sufrimientos, sus invocaciones, sus súplicas; todas las palabras posibles para circunscribir esa experiencia subjetiva en los límites de una inquietante extrañeza, esta experiencia inquietante y luminosa «[...] de una conmoción del ser» ${ }^{6}$ para retomar la expresión formulada por Murielle Gagnebin. Conmoción ${ }^{7}$ que fue bienvenida ya que me implicó en este camino tan apasionante. Más allá de esta aproximación clínica, psicopatológica y psicoanalítica, sobre la cual va a centrarse mi lectura, la exploración del universo de Frida Kahlo se hará aquí en relación a la biografía fílmica titulada Frida [2002], una creación estadounidense, por no decir hollywoodense, en la cual la directora norteamericana Julie Taymor crea una Frida resplandeciente, incandescente, interpretada por la actriz mexicano-estadounidense Salma Hayek.

\section{La cineasta Julie Taymor}

Julie Taymor, nacida el 15 diciembre de 1952, es una directora estadounidense que en 1969 realiza una formación en La Escuela Internacional de Mimo y Teatro Jacques Lecoq en Paris, donde descubre por primera vez el trabajo con máscaras.

En 1974, parte a los Estados Unidos para estudiar teatro y mitología en l'Oberlin College, junto a artistas de renombre.

De 1975 à 1976, crea una Compañía llamada Máscara \& Danza en Indonesia, el Theater Loh, compuesta por músicos, actores, bailarines y marionetistas tanto franceses, alemanes, estadounidenses como javaneses o sudaneses. Julia inicia una gira y recorre el país con dos producciones inéditas: Way of snow y Tirai, las cuales fueron presentadas posteriormente en los Estados Unidos. En 1997, trabaja en la adaptación y puesta teatral del film de los Estudios Disney The Lion King (El Rey León, 1998), una comedia musical que la llevó a ganar un Tony Award por su dirección.

Julia será luego reconocida internacionalmente por el film Frida producido en 2002 donde dirige a Salma Hayek. Este film fue aclamado en distintos festivales de cine internacionales y fue seleccionado para competir en los Oscars. Nominado en varias categorías, el film será galardonado sucesivamente en los siguientes premios: Oscar al mejor maquillaje y peinado y a la mejor banda sonora, Golden Globe a la mejor banda sonora, Satellite Award a la mejor banda sonora. En este film, la cineasta fue acompañada por el director de fotografía Rodrigo Prieto, quien, apasionado por su oficio, se destaca en la investigación visual y el arte de captar la materia, la luz, como también valorar la textura y la calidad estética de los films. Prieto es además reconocido por su uso bastante atípico de la cámara, a menudo asociado a efectos de iluminación expresivos. Gracias a él en el film aparece una fotografía innovadora, donde los colores tornasolados, vivos se mezclan con imágenes crudas en tonos amarillos y pardos. En consecuencia, Julie Taymor \& Rodrigo Prieto crean numerosos efectos especiales con reconstrucciones de los cuadros de la artista o incluso animaciones que otorgan literalmente vida a la obra de la artista.

La directora asume una elección claramente determinada inclinándose por destrezas técnicas tales como la calibración digital de los matices de colores, los efectos tragicómicos, las imágenes sintéticas, que confieren a Frida in fine una dimensión y un aura muy hollywoodense. 


\section{La trama narrativa del film}

Este film biográfico relata la vida de la pintora mexicana inspirándose principalmente en el libro que le dedicó Hayden Herrera ${ }^{8}$. Este relata su tormentosa vida desde su juventud como estudiante de medicina, su accidente, su relación apasionada y tumultuosa con el muralista Diego Rivera, su relación secreta y controvertida con León Trotsky así como sus aventuras homosexuales.

Numerosas referencias a los cuadros de Frida Kahlo están incluidas en la escenografía y recuerdan la riqueza y la complejidad de su obra: más de ciento cuarenta cuadros de los cuales una cincuentena autorretratos se traducen en diferentes temáticas: la política, la mexicanidad, el amor, la naturaleza, el sufrimiento, la femineidad e incluso la muerte.

Un plano en particular, logrado gracias a la destreza técnica de Rodrigo Prieto, despertó especialmente mi interés: Frida en posición fetal después del accidente; un plano que potencia simbólicamente eel nacimiento» o más bien «el renacimiento» de la artista después de esta tragedia. Este «segundo nacimiento» simbólico encuentra un eco en los proyectos de Frida con su novio de aquella época, cuando este la visita luego de su accidente. Ella, refiriéndose al corsé de yeso que le ciñe, le dice: «Después de haber salido de esta crisálida, te voy a mostrar que puedo hacer el amor como antes» mientras que su novio se prepara para partir a Europa.

Al margen, el desafío del biopic consiste en lograr, por un lado, construir, modelar, poner en escena y en imágenes la vida de esta artista fuera de lo común; y por otro lado, permitir al espectador descubrir el entrelazamiento entre la subjetividad creadora y la obra de un artista.

\section{La pasión según Frida}

El film describe el carácter entusiasta e impetuoso de Frida Kahlo, alimentado por su energía revolucionaria y por sus compromisos políticos, por sus relaciones extraconyugales y apasionadas tanto con mujeres como con hombres, por su vida compuesta de dolores y sufrimientos que provocan la admiración de todos quienes la conocieron.

$\mathrm{Al}$ margen de todas las connotaciones significativas de esta biografía fílmica, la artista celebra literalmente el arte como fuerza de trascendencia: entrega su sufrimiento en obras coloridas como espejos que reflejan el propio abismo de su dolor.

\section{La pasión y la incandescencia: un posible lema para este film}

Frida, mujer apasionada, comprometida en cuerpo y alma en la revolución política, artística, sexual, se inscribe en el universo de la pintura de principio del siglo veinte, en un momento de ruptura y creación, donde las transformaciones del mundo artístico suceden a los efectos devastadores de la post-guerra; en particular, el mito de los orígenes, la temática del ciclo de la vida y de la muerte, la desnudez del cuerpo, la fecundidad, la sexualidad y el embarazo son develados como para conjurar toda esta destructividad y confirmar contra viento $y$ marea la superioridad de la vida. Además, Frida Kahlo nos interpela sobre las ideas preconcebidas respecto a las grandes preguntas ligadas al origen de la vida, al conocimiento y a la mortalidad.

Asimismo, los cuadros incluidos en el film Frida y Diego Rivera (1931), Hospital Henry Ford (1932), Unos cuantos piquetitos (1935), El suicidio de Dorothy Hale (1938), Las dos Fridas (1939), Autorretrato con pelo corto (1940), La columna rota (1944), resultan escenificaciones de lo que vive la artista desde su accidente de tránsito sucedido el 17 de septiembre de 1925. Es en ese punto exacto, traumático en efecto, que buscará exorcizar en la pintura los afectos masivos, invasivos, drenados por el dolor psíquico y físico; que se comprometerá en la puesta de sentido exaltada, encarnada de una subjetividad que espera ser reconocida, en su condición ante todo viva, abriendo así la vía del proceso de creación: «Mi vida cambia... Amarillo del sol, blanco del acero, negro del dolor, rojo de la sangre. Los cuatro colores de los puntos cardinales de los antiguos mayas están presentes para celebrar la muerte de Frida la Despreocupada» ${ }^{9}$ se lee en su diario. Frida Kahlo se arrojará en cuerpo y alma -la expresión aquí no es en vano- orientándose hacia la pintura como hacia una suerte de cirngía del alma, que subscribirá desde un principio su realización artística, en el contexto de una ruptura subjetiva traumática: «Largos meses de agonía y al final un renacimiento... estoy clavada a mi cama, incapaz de estar de pie, crucificada por el dolor y la angustia. Mi madre, que fue pintora, instaló un amplio espejo sobre mi cama y así me convertí en mi propia modelo. Lo que mis piernas se niegan, mis manos me lo darán: la fuga. Atravieso el espejo, me alejo de esta cama prisión y empiezo a pintar, pintar, pintar... Frida la Artista ha nacido» ${ }^{10}$, escribió ella.

Es aquí pertinente el término «écheveu» ${ }^{11}$ de una vida y una subjetividad al servicio de la pintura. Resulta pertinente destacar que la definición de écheveu ("en- 
tramado" / "madeja") refiere, por un lado, al «montaje de hebras plegadas y unidas por un hilo de atar»; y por otro, a «un conjunto de elementos diversos enredados», sinónimo de «laberinto» o incluso de «situación complicada»; lo que aquí, en una metáfora elocuente, refleja de manera adecuada el carácter inseparable de la obra y la experiencia subjetiva de la artista. Pero entonces, ¿qué imágenes elegir para llegar a impactar, esta lucha inconsciente pero bien real que sólo la pintura puede mitigar? Es la esencia misma del cine la que es puesta a prueba por esta capacidad de volver verosímil la dinámica psíquica que se juega o incluso la experiencia del vacío del ser en el acto creador y que la artista intenta plasmar en un destello de colores y gamas resplandecientes.

Intentemos un desglose del proceso creador en Frida Kahlo, cuyo momento aparece aquí como una ruptura, en los límites de la grieta subjetiva, tras su segundo aborto espontáneo.

\section{El Hospital Henry Ford o La cama volando}

En la mitad del film aproximadamente tiene lugar la escena del (segundo) aborto espontáneo, que es percibida por el espectador en su dimensión claramente trágica: «El bebé salió en pedazos» le dice Frida a Diego entre lágrimas. Luego, dirigiéndose al médico grita: « $i$ Quiero ver a mi hijo!». El médico accede a su pedido. Efectivamente, en el plano posterior, se ve el feto en un frasco y en un segundo plano, a Frida pintando mientras observa y examina al embrión.

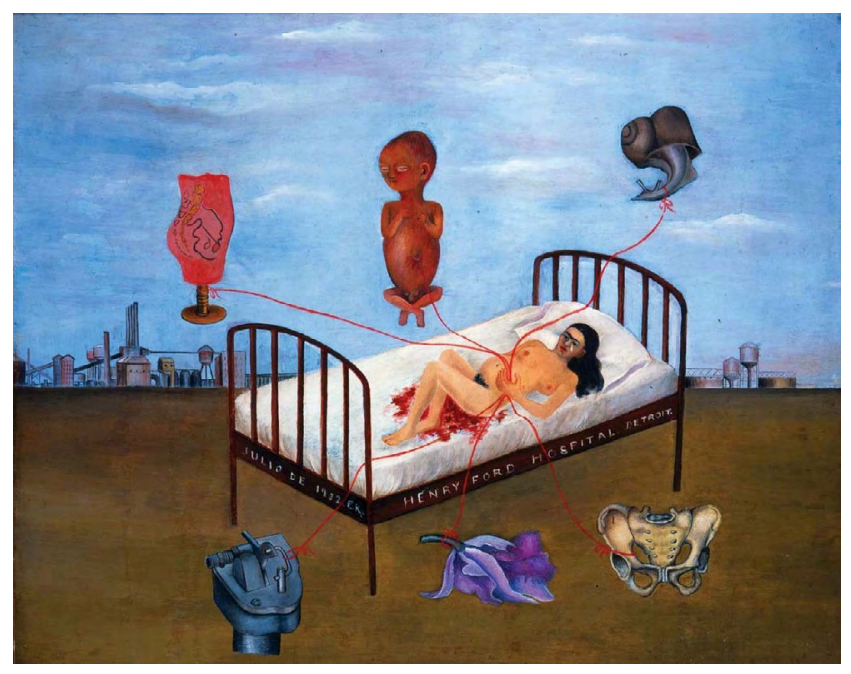

Diego Rivera, que descubre el bosquejo mientras Frida permanece adormecida en su cama de hospital, rompe en llanto: se trata de la obra ${ }^{12}$ Hospital Henry Ford o Cama Volando, obra desgarradora y desconcertante a la vez que contribuye «[...] así de manera privilegiada a «enseñar-nos» ${ }^{13}$ en la acepción fuerte que Lacan le da a ese término en el sentido que para la artista: «El objeto de la creación [...] pretende hacer existir un real, un mundo fuera en el corazón del mundo» ${ }^{14}$ que constituiría luego en cierto modo «su remedio» ${ }^{15}$.

Aquí, observamos que la artista se expone en su intimidad corporal sin límite frente al espectador: esta escena trágica coloca este lienzo bajo el símbolo de la soledad, del dolor, de la pérdida donde la vida no puede nacer. Más que toda obra, «es esta mezcla de crudeza y artificio $[\ldots]{ }^{16}$ pero también de puesta en escena, que despliega este lienzo una intensidad singular... y muestra su carácter inédito.

Semejante puesta en escena merece que nos detengamos: la construcción de este cuadro sobre el modo exvoto, pone el acento en la necesidad y hasta quizás en la urgencia de contar y de mostrar un evento, y no en privilegiar el efecto estético. Es en ese sentido que la artista habría logrado aquí captar su experiencia, para hacer de ella la materia singular de un estilo firmemente innovador que marca una temporalidad inédita.

Este lienzo va a representar un punto de inflexión en la carrera de la artista: formulo entonces como hipótesis que la pintura constituiría aquí un intento desesperado de consolarse por este embarazo abortado «[...] y que en el futuro la creación artística sustituiría a la maternidad» ${ }^{17}$ constituyendo un hito, marcando una temporalidad nueva en su arte pictórico. Asimismo, esta hipótesis se intensifica con otra, según la cual, incluso si la principal instancia de la creación «[...] es la pieza faltante» ${ }^{18}$ en el sentido de Paul-Laurent Assoun, es decir aquella en donde se precipitó lo real incognosible, la obra no viene a embellecer cualquier realidad: «Sostiene el mundo según para autor» ${ }^{19}$ en el sentido donde el objeto creado sería el medio de ligar las pulsiones de vida y de muerte. Dicho de otra forma por este mismo autor a quien cito: «el artista - «el creador»- es aquel que está retenido al borde del síncope por su obra» ${ }^{20} \mathrm{o}$ incluso el colapso, el estallido, la pérdida.

Esta obra Hospital Henry Ford marca a mi entender una ruptura de orden psíquico pero Frida Kahlo consigue al mismo tiempo expresar el motivo de su sufrimiento, ¿para proporcionarle un contenido de representación? ¿ «Esta exhibición vuelta de sí en la obra» ${ }^{21}$ permite una real elaboración incluso del exceso de esta experiencia traumática de pérdida? 
Aquí, el espectador se encuentra directamente interpelado por el cuerpo sufriente: este lienzo ofrece a la vista una cáscara carnal dañada, la fragmentación de partes invita a la irrupción presentando la discontinuidad del cuerpo. Por la vía de la externalización de los órganos, este lienzo transmite su esencia trágica. ¿ No se podría igualmente leer «[...] la confesión más o menos consciente de una cierta impotencia» ${ }^{22}$ a desplegar en el espacio de la tela ese «no-lugar», esta experiencia de sinsentido como real inherente al evento traumático del aborto?

Lo cual testimonia también de cierta forma David Lomas ${ }^{23}$ cuando escribe: «Es posible que para Kahlo la experiencia de un aborto pudiese servir como confirmación de esta exclusión de lo femenino del lenguaje. Pero donde quizás la podemos ver abandonando la compañía de Lacan es en su intención de re-trabajar y transformar el sistema patriarcal de representaciones, un proyecto en el que su propia identidad está en juego».

No obstante, en este instante de suspensión donde lo simbólico no opera más, algo de lo inédito va a poder sin embargo ser producido... y creado: pintar funcionaría como una presencia y le permitirá no hundirse: «Pinto flores para que así no mueran» afirmaba Frida Kahlo en una sublime metáfora.

El recorte de esta secuencia cinematográfica, que pone en escena y en imágenes el segundo embarazo, luego el aborto (por el cual vivirá un calvario de quince días) y la producción de este lienzo Hospital Henry Ford mientras que Frida está todavía en cama, minimiza esta tragedia profunda, pulsional, psíquica, aquella de una doble pérdida: el bijo deseado que la habría hecho madre. Tragedia que es parte integrante de un trauma cuyo desafío será aquí transformarlo en acto creador.

El talento de Julie Taymor consiste sin lugar a dudas en haber inscripto la compleja problemática de Frida Kahlo en un contexto socio político significativo; pero también de haber galvanizado la potencia deslumbrante de su temperamento con la justeza de su relación matrimonial. Dando a conocer un avatar específico del film hollywoodense, el brillo de la artista en detrimento del posible encuentro perturbador de su pintura.

En consecuencia, la aproximación más profunda de la ruptura subjetiva de la artista, la trama dramática de este periodo de 1932 -tal como es reconstruida aquí- retiene solamente el elemento del aborto al igual que otros eventos vividos por la artista. Para decirlo en otras palabras, el carácter algo trivializado del aborto «vela» el trasfondo de esta escena violenta grabada al rojo vivo: el mal encuentro del real en el sentido lacaniano y la fijación de este real como principio de muerte, en virtud del vacío que abre e indaga in fine el cuadro: «Detenerse en lo imposible», «apuntar a lo real», «mostrar el agujero», es propio del arte y su verdad», tal como lo escribe Anne Juranville. ${ }^{24}$

\section{Para concluir}

Miramos, pero vemos también, la vida de Frida Kahlo de otra manera desde que fue objeto de este film autobiográfico. El desafío para Julie Taymor era de concentrar la intensidad de su existencia en un film, evitando en la medida de lo posible una percepción muy ilustrativa o muy académica, dos escollos que acechan al biopic.

Pero se puede lamentar que el film no da suficientemente cuenta de la problemática -el trauma- fundante de su subjetividad creadora, re-articulada a la escena del accidente de bus. Podría haberse hecho más hincapié en el tratamiento traumático que combine la falla del sujeto y el goce de su deseo de artista que lleva en él «un desequilibrio» evidente, el de un desgarro subjetivo de esencia traumática. En una fórmula lapidaria pero esclarecedora, una amiga íntima de la artista decretó un día: «Dedicó su vida a morir» ${ }^{25}$ para dar testimonio de la batalla agotadora de Frida Kahlo contra una degradación física y corporal tortuosas, un agotamiento incesante, un dolor constante. Un sufrimiento permanente del cual el film, paradójicamente, no da mucha cuenta, salvo al final.

El hecho que Julie Taymor se interese más en el exceso del evento traumático y el «después del accidente» como el «después del aborto» augura finalmente una versión muy contemporánea de esta construcción narrativa.

En otras palabras, es lo que considero como un doble trauma: el accidente de bus y el (segundo) aborto parecen confinados en este relato, mientras que podrían haber sido considerados el epicentro de una reflexión absolutamente fecunda sobre una trayectoria psíquica y pictórica indisociables.

Sin embargo, Julie Taymor hizo una elección claramente determinada, a saber, una parcialidad estética: logró, con este film, un retrato viviente y conmovedor de una mujer que devino objeto de culto en el mundo entero. Promueve el uso y la (re)creación de las obras 
más conocidas que aseguran un seguimiento cronológico de la vida de la artista. Su taller de pintura aparece como un microcosmos que permite condensar conceptos artísticos del período correspondiente y escenificar la sociedad, sus actores, sus costumbres o crear un espacio pictórico determinado por el encuadre de la cámara.
En fin, como último logro, la realizadora hace del lienzo El Sueño (1940) una imagen final impregnada de gracia, de poesía trascendida al igual que angustiosa, que celebra una Oda a la vida. Aquello de lo que la artista dio testimonio: de lo vivido, con entrega, audacia y celeridad.

\section{Traducción: Carolina Kasimierski}

\section{Referencias}

Assoun, P.-L. (2004). «La « création » à l'épreuve de la métapsychologie. L’objet inconscient de la création », in Céline Masson, Psychisme et création, Collection « Perspectives Psychanalytiques ». Paris: L’Esprit du temps. 17-41.

Chouvier, B. (2004). «Processus de création et objets œuvrés », in Céline Masson, Psychisme et création, Collection « Perspectives Psychanalytiques ». Paris, L'Esprit du temps. 67-85.

Crenn, J. (2008). «Frida Kahlo, La chair ouverte ». En Genre E Histoire, 2, 1-11.

Festino-Cassata, R. (2013). Les voies de la mélancolie et de la création chez Chaïm Soutine, le « violeur de couleurs. Radioscopie d'un acte de peinture. Sous la Direction du Professeur Anne Juranville, Thèse de Doctorat en Psychologie Clinique, Université de Nice Sophia-Antipolis.

Gagnebin, M. (1984). L'irreprésentable ou les silences de l'œuvre. Paris: PUF, Collection L'écriture.

Herrera, H. (1983). FRIDA. Une biographie de Frida Kablo. Paris: Flammarion.

Juranville, A. (2009). “La sensation dans le processus visionnaire de la création chez Virginia Woolf”, dans Cliniques Méditerranéennes, $80,81-95$.

Juranville, A. (2017). “Chaïm Soutine. La mélancolie du « dernier peintre maudit”. dans La psychanalyse à l'épreuve de l'art. Le féminin, le procès de la création. Saarbrücken. Éditions universitaires européennes, 127-141.

Le journal de Frida Kahlo (1995). Introduction de Carlos Fuentes. Paris: Éditions du Chêne.

Lomas, D. (2001). "Lenguajes corporales : Kahlo y la imaginería médica”. En Karen Cordero y Inda Saenz, (compiladoras), Crítica feminista en la teoría e historia del arte, Mexico, 327-343. Recuperado de: https://sentipensaresfem.wordpress.com/2016/09/10/cftha/

Riazuelo-Deschamps, H. (2007). Anthropologie et psychanalyse de la grossesse. Représentations maternelles au cours d'une première et d'une deuxième grossesse. Sous la Direction du Professeur Dominique CUPA, Thèse de Doctorat en Psychologie Clinique, Université de Paris X Nanterre.

Tibol, R. (2007). “Lettres à Alejandro Gómez Arias”, dans Frida Kahlo par Frida Kahlo. Paris: Éditions Christian Bourgeois, 58-64.

${ }^{1}$ Tibol, R. 2007. « Lettres à Alejandro Gómez Arias », dans Frida Kahlo par Frida Kahlo, Paris, Éditions Christian Bourgeois, p.61. ${ }^{2}$ Le journal de Frida Kahlo, Introduction de Carlos Fuentes, Paris, Éditions du Chêne, 1995, p.14.

${ }^{3}$ Adepto al dolorismo. Tendencia a exaltar el dolor físico y atribuirle un valor moral o religioso.

${ }^{4}$ Crenn, J. 2008. « Frida Kahlo, La chair ouverte », dans Genre \& Histoire, 2/2008, p.2.

${ }^{5}$ Exposition Frida Kahlo et Diego Rivera au Musée National de l’Orangerie, Paris, 9 octobre 2013-13 janvier 2014.

${ }^{6}$ Gagnebin, M. 1984. L’irreprésentable ou les silences de l'œuvre, Paris, PUF, Collection L'écriture, p.5.

${ }^{7}$ Bouleversement, explosion, choc.

${ }^{8}$ Herrera, H. 1983. FRIDA. Une biographie de Frida Kahlo, Paris, Flammarion, 2013.

${ }^{9}$ Le journal de Frida Kahlo, Introduction de Carlos Fuentes, Paris, Éditions du Chêne, 1995.

${ }^{10}$ Le journal de Frida Kahlo, Introduction de Carlos Fuentes, Paris, Éditions du Chêne, 1995.

${ }^{11}$ Festino-Cassata, R. 2013. Les voies de la mélancolie et de la création chez Chaïm Soutine, le « violeur de couleurs. Radioscopie d'un acte de peinture. Sous la Direction du Professeur Anne Juranville, Thèse de Doctorat en Psychologie Clinique, Université de Nice Sophia-Antipolis, p.15.

${ }^{12}$ Henry Ford Hospital está fechado en 1932.

${ }^{13}$ Juranville, A. 2009. «La sensation dans le processus visionnaire de la création chez Virginia Woolf », dans Cliniques Méditerranéennes, 80/2009, p.81. 
${ }^{14}$ Assoun, P.-L. 2004. «La «création » à l'épreuve de la métapsychologie. L’objet inconscient de la création », in Céline Masson, Psychisme et création, Paris, L'Esprit du temps, Collection « Perspectives Psychanalytiques », p.31.

${ }^{15}$ Ibid., p.35.

${ }^{16}$ Herrera, H. 1983, Op. cit., p.101.

${ }^{17}$ Herrera, H. 1983, Op. cit., p.182.

${ }^{18}$ Assoun, P.-L. 2004. «La «création » à l'épreuve de la métapsychologie. L’objet inconscient de la création », in Céline Masson, Psychisme et création, Paris, L’Esprit du temps, Collection « Perspectives Psychanalytiques », p.33.

${ }^{19}$ Ibid., p.33.

${ }^{20}$ Ibid., p.39.

${ }^{21}$ Chouvier, B. 2004. « Processus de création et objets œuvrés », in Céline Masson, Psychisme et création, Paris, L'Esprit du temps, Collection «Perspectives Psychanalytiques », p.69.

${ }^{22}$ Gagnebin, M. 1984, Op. cit., p.177.

${ }^{23}$ Lomas, D. 2001. «Lenguajes corporales : Kahlo y la imaginería médica », in Karen Cordero \& Inda Saenz, (compiladoras), Crítica feminista en la teoría e historia del arte, Mexico, p.328.

${ }^{24}$ Juranville, A. 2017. «Chaïm Soutine. La mélancolie du « dernier peintre maudit », dans La psychanalyse à l'épreuve de l'art. Le féminin, le procès de la création, Saarbrücken, Éditions universitaires européennes, p.137.

${ }^{25}$ Herrera, H. 1983, Op. cit., p.85. 